\title{
Influence of drying temperature and ultrasound application in some quality properties of apple skin.
}

\author{
Martins, M. a*; Cortés, E. ${ }^{\text {b }}$;imal, Sc $^{\text {; }}$ Mulet, A. ${ }^{\text {d }}$ Pérez-Muelas, N. ${ }^{\text {d }}$ Cárcel, J. A. ${ }^{\text {d }}$ \\ ${ }^{a}$ Department of Food Engenieering. Faculty of Animal Science and Food Engineering, University of \\ Sao Paulo, São Paulo, Brazil. \\ b Technological Institute of Veracruz, Veracruz, México \\ ${ }^{c}$ Department of Chemistry. University of the Balearic Islands, Palma, Spain. \\ ${ }^{d}$ ASPA group. Department of Food Technology. Universitat Politècnica de València, Valencia, Spain \\ *E-mail of the corresponding author: matheuspmartinss@gmail.com
}

\begin{abstract}
The great amount of waste produced by the food industry can be an interesting source of bioactive compounds. To this end, convective drying is one of the most extended method to stabilize the industrial by-products. However, drying conditions can affect not only drying kinetics but also the bioactivy of some compounds. Apple skin constitutes one of the main byproduct generated in apple juice or cider production. It contains important amounts of functional compounds such as polyphenols or vitamin $C$ whose extraction can be interesting. The main aim of this work was to determine the influence of drying conditions, temperature and application of ultrasound, in some quality parameters of dried apple skin. For this purpose, apple skin samples were dried at different temperatures $\left(-10,30,50\right.$ and $\left.70^{\circ} \mathrm{C}\right)$ and with $\left(20.5 \mathrm{~kW} / \mathrm{m}^{3}\right)$ or without application of ultrasound. Color, total phenolic content, antioxidant activity and vitamin $C$ was measured in fresh and dried samples. The increase of drying temperature and the ultrasound sligthly reduced the antioxidant properties of samples while no influence in sample color was observed.
\end{abstract}

Keywords: by-product; antioxidant; polyphenol; vitamin C; color. 


\section{Introduction}

The high volume of waste produced in the actual food industries has a great environmental impact. However, in many cases, the waste can be considered as a by-product that constitute a source of interesting bioactive compounds.[1]

Apple is one of the most popular fruits in the world being consumed such as fresh fruit, jam, baby food, juices or snacks. In this sense, apple skin constitutes one of the main byproducts generated in the apple industrialization. Apple skin contains great amounts of compounds with high antioxidant capacity, even greater than those present in the flesh.[2, 3 , 4] In fact, apple skin can be directly used as a functional ingredient of other food products. $[5,6]$. To facilitate the storage and the manage, apple skin must be stabilized and for this purpose convective hot air drying is one of the most applied.[7] However, the temperatures and the long time of processing can damage flavor, nutritional composition or look of dried product.[2, 8]. In fact, the influence about drying process on antioxidant activity of apples and been previously studied not ontly in apple flesh $[9,10,11]$ but also in apple skin.[2] Taking into account the final quality of the product, the drying processes at low temperatures emerges as an excellent alternative. However, the low drying rate at this contidions makes necessary the search of methos to intensify the process [22, 23]. In this sense, ultrasound application constitutes an efficient way to intensify mass transport which can shorten the processing time.[12] Moreover, the effects of ultrasound are mainly mechanical which dn't produce a significant heating of the samples.[13]

The main aim of this work was to assess the influence of the drying temperature and ultrasound application on the color and the antioxidant properties of apple skin.

\section{Materials and Methods}

\subsection{Sample preparation}

Apples (Royal Gala var.) of similar ripness state were choosen in a local market (Valencia, Spain). The fruits were washed with tap water and peeled using a household peeler. After that, the samples of apple skin were blanched for $30 \mathrm{~s}$ in boiling water in order to inactivate the enzyme polyphenol oxidase.[14] Initial moisture content was determined after maintaining apple samples in a vaccumm oven at $60^{\circ} \mathrm{C}$ until constant weight [15].

\subsection{Drying}

Experiemntal drying processes was carried out at atmospheric freeze-drying and at hot air drying conditions. 


\subsubsection{Atmospheric freeze-drying experiments}

Apple skin samples were placed in a holder with regular distribution that assure the homogeneity of air flow and ultrasound treatment during drying process. After, the set was introduced in a blast freezer (HIBER, mod. ABB BF051, Italy) where samples were frozen at $-35 \pm 1^{\circ} \mathrm{C}$. Later, the frozen samples were placed in an ultrasonically-assisted convective drier [22] where drying experiments were carried out at $-10^{\circ} \mathrm{C}$ and $2 \mathrm{~m} / \mathrm{s}$, without (AIR-10) and with (US-10; $50 \mathrm{~W} ; 21.9 \mathrm{kHz}$ ) ultrasound application. Experiments ended when samples lost $85 \%$ of initial weight.

\subsubsection{Hot air drying experiments}

Fresh apple skin samples where placed in a similar holder than the used for atmosphericfreeze drying experiments, and placed in a dryer assisted with ultrasound [16]. Drying experiments $(2 \mathrm{~m} / \mathrm{s})$ were conducte at 30,50 and $70^{\circ} \mathrm{C}$, without (AIR30, AIR50 and AIR70) and with (US30, US50, US70; $50 \mathrm{~W} ; 21.7 \mathrm{kHz}$ ). All the conditions tested were carried out by triplicate.

\subsection{Quality parameters}

\subsubsection{Color}

Apple skin sample color was assesd by measuring the CIELab parameters $\mathrm{L}^{*}$ (lightness/darkness), $\mathrm{a}^{*}$ (redness/greenness) and $\mathrm{b}^{*}$ (yellowness/blueness) with the help of a colorimeter CM-2500d (Konica Minolta, Japan). All readings were done in triplicate using a D65 illuminant reference system. Chroma was estimated from Eq. 1.

$$
C^{*}=\sqrt{\left(a^{* 2}+b^{* 2}\right)}
$$

\subsubsection{Antioxidant properties}

An extract of dried apple skin was obtained for measuring antioxidant properties. For this purpose $3 \mathrm{~g}$ of sieved powder of apple peel were placed in $25 \mathrm{~mL}$ of an ethanol $(96 \% \mathrm{v} / \mathrm{v})$. (3,5 $\mathrm{g}$ of apple's peel powder in $10 \mathrm{~mL}$ of ethanol $(96 \% \mathrm{v} / \mathrm{v})$ in the cas of acorbic acid measurements). The mix was introduced in an ultrasonic cleaner bath (VMR mod. USC-T, USA) forg $15 \mathrm{~min}$. After that, the samples were filtered using nonsterile hydrophobic PTFZ syringe filters of $4.5 \mu \mathrm{m}$ (VMR, USA).

\subsubsection{Antioxidant capacity}

Antioxidant Capacity (AC) of the apple skin was determined by the Ferric-Reducing Ability Power (FRAP) method, which was described by Benzie and Strain.[17] The results were expressed as mmol Trolox equivalent per g of dry mass of apple skin. 


\subsubsection{Total Phenolic Content}

The Total Phenolic Content (TPC) of the apple's peel extracts was determined following the Folin-Ciocalteau method.[18] In this case, the results were expressed as mg of Gallic acid equivalent (GAE) per $g$ of dry mass of apple skin.

\subsubsection{Ascorbic Acid content}

The Ascorbic Acid content (AA) was determined adapting the method proposed by Jagota y Dani [19], and expressed as mg of ascorbic acid content per $g$ of dry mass of apple skin. Every measurements were done in triplicate.

The percentage of retention of the different antioxidant parameters was estimated (Eq. 2)

$$
\text { Retention }=\frac{P_{f}}{P_{0}} \cdot 100
$$

where $\mathrm{P}_{0}$ is the value of the parameter obtained (AC, TPC and AA) from fresh apple skin and $\mathrm{P}_{\mathrm{f}}$ from the different dried apple skin samples.

\section{Results and Discussion}

\subsection{Color measurements}

The measuerements of apple skin sample color showed that in the AIR experiments, samples dried at the greater drying temperature presented higher luminosity but lower redness and yelowness (Fig. 1). The results obtained at the lower temperature tested were the opposite, being samples less luminous, but with higher values of redness and yellowness attributes being these last characteristics more appreciated for the apple skin of the Royal Gala apple variety.

As for the ultrasound influence on the color, the parameters obtained in US-10 experiments were similar than the obtained at AIR50. The mechanical stress produced by ultrasound over the frozen samples during the long drying period may be the reason for this result. In the case of US30, US50 and US70, the relationship between color parameters and temperature was similar than for AIR experiments.

Regarding the chroma, in the case of AIR experiments, the highest value was obtained at the lowest drying temperature tested, decrasing its value with the increase temperature. (Fig. 1). In the case of US experiments, the US-10 experiments showed significant $(\mathrm{p}<0.05)$ lower chroma value than those found at AIR-10. However, at temperatures above freezing point, the application of ultrasound increased the chroma value. In fact, the value obtained in US30 experiments was not significantly different that the obtained in AIR-10, showing 
that is possible to achieve the same saturation color in this condition that at atmospheric freeze-drying condition but in a shorter process time.

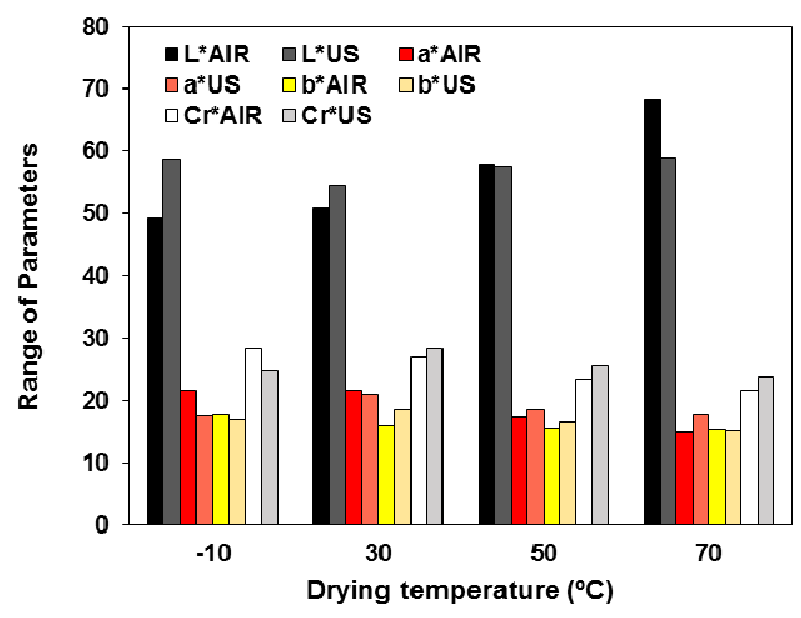

Figure 1. CieLAB Color parameters and chroma of apple skin dried at different temperatures without or with $(50 \mathrm{~W})$ ultrasound application.

\subsection{Antioxidant Capacity (AC)}

The antioxidant capacity (AC) of the fresh apple peel was $42 \pm 1 \mathrm{mg}$ Trolox/g d.m, being this value higher than those obtained for other authors in apple's flesh.[10, 11, 12] On the contrary, the retention of AC after drying was in the range.[10, 11, 12]

No seignificant difference wer found about AC retention among the samples dried at different conditions except for AIR30 ones (Table. 1). In this conditions, samples showed a significant $(\mathrm{p}<0.05)$ higher percentage of AC retention. In general, the application of ultrasound dind't signficanly affect the AC retention. Therefore, the use of ultrasound can be interesting to reduce drying temperature without significantly affect the AC retention.

\subsection{Total Phenolic Compounds (TPC)}

The TPC content of dried apple skins was $16.6 \pm 0.9 \mathrm{mg}$ de GAE/ $\mathrm{g} \mathrm{d} . \mathrm{m}$, being in the range found for fresh apple skin by Lata [20], and slightly lower than those found by Henriquez et al. [2]. As expected, the drying process reduced significantly the TPC (Table. 1). Above freezing point, the higher the temperature the lower the TPC retention showing the termosensibility of TPC.[2] Regarding the atmospheric-freeze dried samples, TPC of AIR-10 samples was not significantly different than the TPC of AIR50 ones. The previous freezing of AIR-10 samples could contribute to the rupture of some cells increasing the phenolic compounds degradation. The long time spent in this type of drying process could also increase the TPC degradation. 
The ultrasound application generated a slightly decrease of the TPC retention. The mechanical stress induced by ultrasound can be responsible of this slight degradation of phenolic compound being this effect more significant when other adverse effects such as high temperature or freein were less important. Santacatalina et al. [9] also found similar effects of ultrasound application in dried apple flesh.

\subsection{Ascorbic Acid content}

The ascorbic acid (AA) content obtained of fresh apple peel was $1.6 \pm 0.2 \mathrm{mg}$ of ascorbic acid/g d.m. As was already expected, the drying produced a partial degradation of this propertie, being the percentage of retention in the range than those found by Moreno et al.[11] In AIR processes above freezing point, the lower the temperature the greater the percentage of AA retention (Table. 1). At $-10^{\circ} \mathrm{C}$, the long dying time and the previous freezing of sample can explain the greater AA degradation. Therefore, regarding the antioxidant properties of dried apple skin, the atomospheric-freeze drying is not the more adequate drying method.

As for ultrasound application, no significant $(\mathrm{p}<0.05)$ effect on AA retention was observed except when drying took place at $70^{\circ} \mathrm{C}$. In this case, the retention in US70 experiment was significantly $(\mathrm{p}<0.05)$ higher than AIR70 process, although these differences were small.

Table 1. Percentage of retention of total phenolic content, antioxidant capacity and ascorbic acid of apple peel after been dried at different temperature with and without ultrasound application.

\begin{tabular}{cccc}
\hline \multirow{2}{*}{ Treatment } & \multicolumn{3}{c}{ \% retention } \\
\cline { 2 - 4 } & AC & TPC & AA \\
\hline AIR-10 & 61.8 & 64.0 & 59.8 \\
AIR30 & 78.9 & 84.9 & 88.7 \\
AIR50 & 59.4 & 73.4 & 61.3 \\
AIR70 & 62.0 & 59.0 & 55.0 \\
US-10 & 60.5 & 61.1 & 60.8 \\
US30 & 69.2 & 62.3 & 88.9 \\
US50 & 58.9 & 66.3 & 58.9 \\
US70 & 67.2 & 50.8 & 68.5 \\
\hline
\end{tabular}

\section{Conclusion}

Drying temperature and ultrasound application affected the apple skin quality. The results obtained showed that the atmospheric freeze-drying was not an interesting drying method for both the long processing time and the no-significant influence on qualtity attributes tested, color and antioxidant properties. General speaking, the influence of ultrasound application during drying on quality attributes was negligible. Then, it constitutes an interesting way to intensify drying process and could permit the reduction of drying 
temperature, which can means a energy needs reduction. However ,this last fact must be deeply studied.

\section{Acknowledgements}

The authors acknowledge the financial support of INIA-ERDF throughout the project RTA2015-00060-C04-02

\section{References}

[1] Martins, N.; Ferreira, I. C.F.R. Wastes and by-products: Upcoming sources of carotenoids for biotechnological purposes and health-related applications. Trends in Food Science \& Technology. 2017, 62, 33-48.

[2] Henríquez, C.; Córdova, A.; Almonacid, S.; Saavedra, J. Kinetic modeling of phenolic compound degradation during drum-drying of apple peel by-products. Journal of Food Engineering. 2014, 143, 146-153.

[3] Karaman, S.; Tütem, E.; Baskan, K. S.; Apakb, R. Comparison of antioxidant capacity and phenolic composition of peel and flesh of some apple varieties. Journal of the Science of Food and Agriculture. 2013, 93: 867-875

[4] Escarpa, A.; Gonzalez, M.C. High-performance liquid chromatography with diodearray detection for the determination of phenolic compounds in peel and pulp from different apple varieties. Journal Chromatography. 1998, vol. 823, no. 1-2, p. 331-337.

[5] Rupasinghe, H.P.V.; Wang, L.; Huber, G.M.; Pitts, N.L.. Effect of baking on dietary fibre and phenolics of muffins incorporated with apple peel poder. Food Chemistry. 2008, 107, 1217-1224

[6] O'Shea, N.; Arendt, E.K.; Gallagher, E. Dietary fibre and phytochemical characteristics of fruit and vegetable by-products and their recent applications as novel ingredients in food products. Innovative Food Science and Emerging Technologies. 2012, 16, 1-10

[7] Moses, J.A.; Norton, T.; Alagusundaram, K.; Tiwari, B.K. Novel Drying Techniques for the Food Industry. Food Engineering Reviews. 2014, 6, 43-55

[8] Lewicki, P. P.; Jakubczyk, E. Effect of hot air temperature on mechanical properties of dried apples. Journal of Food Engineering. 2004, 64, 307-314.

[9] Santacatalina, J.V.; Rodríguez, O.; Simal, S.; Cárcel, J.A.; Mulet, A.; García-Pérez J.V. Ultrasonically enhanced low-temperature drying of apple: Influence on drying kinetics and antioxidant potential. Journal of Food Engineering. 2014, 138, 35-44 
[10] Rodríguez, O.; Santacatalina, J.V.; Simal, S.; Garcia-Perez, J.V.; Femenia, A.; Rosselló, C. Influence of power ultrasound application on drying kinetics of apple and its antioxidant and microstructural properties. Journal of Food Engineering. 2014, 129, 21-29.

[11] Moreno, C.; Brines, C.; Mulet, A.; Rosselló, C.; Cárcel, J. A. Antioxidant potential of atmospheric freeze-dried apples as affected by ultrasound application and sample surface. Drying Technology. 2017, 35(8), 957-968

[12] Musielak, G.; Mierzwa, D.; Kroehnke, J. Food drying enhancement by ultrasound - A review. Trends in Food Science \& Technology. 2016, 56, 126-141.

[13] Cárcel, J.A.; García-Pérez, J.V.; Riera, E.; Rosselló, C.; Mulet, A. Ultrasonically assisted drying. In Ultrasound in Food Processing; Villamiel, M., García-Pérez, J.V., Montilla, A., Cárcel, J.A., Benedito, J., Eds.; John Wiley \& Sons Ltd.: United Kingdom, 2017; pp 371-391.

[14] Wolfe, K.L.; Liu, R.H. Apple Peels as a Value-Added Food Ingredient. Journal of Agricultural and Food Chemistry. 2003, 51, 1676-1683

[15]AOAC, Association of Official Analytical Chemist. Official methods of analysis; Arlington: EEUU, 1997.

[16]Riera, E.; García-Pérez, J.V.; Acosta, V.M.; Cárcel, J.A.; Gallego-Juárez, J.A. A computational study of ultrasound-assisted drying of food materials. In: Knoerzer, K., Juliano, P., Roupas, P., Versteeg, C. (Eds.), Multiphysics Simulation of Emerging Food Processing Technologies. IFT Press, Chicago, USA, 2011; pp. 265-302.

[17]Benzie, I.F.; Strain, J.J. The ferric reducing ability of plasma (FRAP) as a measure of "antioxidant power": the FRAP assay. Anal. Biochem. 1996, 239, 70-76.

[18]Gao, X.; Bjork, L.; Trajkovski, V.; Uggla, M. Evaluation of antioxidant activities of rosehip ethanol extracts in different test systems. J. Sci. Food Agric. 2000, 80, 20212027.

[19] Jagota, S.K.; Dani, H.M. A new colorimetric technique for the estimation of vitamin C using Folin phenol reagent. Analytical Biochemistry. 1982, 127(1), 178-182.

[20] Lata, B. Relationship between Apple Peel and the Whole Fruit Antioxidant Content: Year and Cultivar Variation. Journal of Agricutlrual and Food Chemistry. 2007, 55, 663-671. 